\title{
ANALISIS USAHATANI BAYAM \\ (STUDI KASUS DI KELURAHAN SASA KECAMATAN TERNATE SELATAN KOTA TERNATE)
}

\author{
Haryati La Kamisi \\ Staf Pengajar FAPERTA UMMU-Ternate,e-mail: ilman_haq23@yahoo.com
}

\begin{abstract}
ABSTRAK
Penelitian dilakukan di Kelurahan Sasa Kecamatan Ternate Selatan Kota Ternate yang bertujuan untuk menganalisis biaya, penerimaan, pendapatan, $R / C$ ratio, dan BEP dari usahatani tanaman bayam. Data dianalisis untuk menganalisis biaya, penerimaan, pendapatan, $R / C$ ratio, dan BEP. Hasil analisis menunjukkan biaya total sekali produksi usahatani tanaman bayam yaitu sebesar Rp. 16.405.000,- yang terdiri dari biaya variabel sebesar $R p$. 6.040.000,- dan biaya tetap sebesar $R p$. 10.365.000,-. Penerimaan dari masing-masing jenis bayam dalam sekali produksi, antara lain : Bayam merah sebesar Rp. 18.000.000,- dan bayam hijau sebesar Rp. 22.500.000,-. Jadi penerimaan total dari produksi bayam secara keseluruhan adalah sebesar Rp.40.500.000,-. Pendapatan total dari usahatani tanaman bayam dalam sekali produksi yaitu sebesar Rp. 24.095.000,-. Nilai $R / C$ rasio usahatani tanaman bayam sebesar 2,4687. Ini menunjukkan usahatani tersebut efisien dan menguntungkan sehingga layak dikembangkan. Nilai Break Even Poin (BEP) penerimaan, produksi, dan harga lebih kecil dari total penerimaan, produksi, dan harga. Dengan demikian usahatani tanaman bayam dapat menguntungkan dan layak dikembangkan.
\end{abstract}

Kata Kunci: Biaya, Penerimaan, Pendapatan, R/C Ratio, BEP

\section{PENDAHULUAN}

1.1. Latar Belakang

Dewasa

ini

pemerintah

menumpahkan harapan pada sektor pertanian umumnya dan khususnya pada jenis tanaman hortikultura, yang merupakan salah satu sumber pertumbuhan baru pada sektor pertanian. Komoditi hortikuktura selain sebagai sumber nutrisi juga mempunyai nilai tukar yang relatif tinggi, sehingga mampu meningkatkan perekonomian masyarakat. Kemampuan komoditi hortikultura dalam memberikan peluang kesempatan kerja dan peluang peningkatan pendapatan secara nyata dapat dilihat, paling tidak dari adanya perubahan pola penggunaan lahan yang lebih difungsikan untuk hortikultura yang semakin sering dan mudah ditentukan (Anonim, 1994).

Pengembangan usahatani tanaman hortikultura terutama jenis sayur-sayuran terlihat telah dirasakan urgensinya. Petani lebih banyak mengusahakan jenis sayursayuran bila dibandingkan dengan jenis hortikultura lainnya. Hal ini karena mudah dikelola dan cepat mendapatkan hasilnya. Oleh karena itu pembinaan untuk pengembangan sayur-sayuran ini harus dilakukan dengan pola pembinaan yang terpadu, baik dibidang produksi, pemasaran dan sarana/prasarana (Saastratmadja,1991).

Tanaman bayam merupakan salah satu jenis tanaman hortikultura yang dewasa ini digemari oleh masyarakat luas, karena 


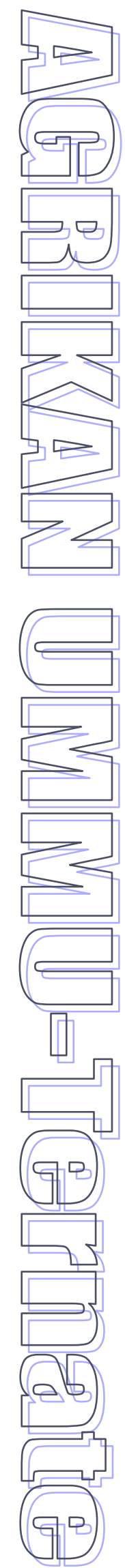

mempunyai nilai gizi yang tinggi. Tanaman bayam sangat mudah dikenali, yaitu berupa perdu yang tumbuh tegak, batangnya tebal berserat dan pada beberapa jenis mempunyai duri. Daunnya bisa tebal atau tipis, besar atau kecil, berwarna hijau atau ungu kemerahan (pada jenis bayam merah). Bunganya berbentuk pecut, muncul di pucuk tanaman atau pada ketiak daunnya. Bijinya berukuran sangat kecil berwarna hitam atau cokelat dan mengkilap (Rukmana, 2005).

\subsection{Tujuan Penelitian}

Penelitian ini bertujuan untuk :

1. Menganalisis besar pendapatan yang diterima petani dalam berusahatani tanaman bayam.

2. Menganalisis tingkat kelayakan usahatani tanaman bayam.

\subsection{Manfaat penelitian}

1. Sebagai bahan informasi bagi petani tanaman bayam dalam mengembangkan usahataninya.

2. Sebagai bahan informasi bagi peneliti dan dapat digunakan sebagai pengembangan ilmu.

3. Sebagai bahan referensi dan bahan studi bagi pihak-pihak lain yang membutuhkan.

\section{METODE PENELITIAN}

1.1. Jenis dan Sumber Data

Jenis data yang dikumpulkan meliputi data primer dan data sekunder. Data primer dikumpulkan dengan menggunakan dua cara yaitu Observasi dan Wawancara. Observasi (Pengamatan), yaitu dengan cara melakukan pencatatan secara cermat dan sistematis, langsung di lokasi objek penelitian yang berkaitan dengan kegiatan yang dilakukan dalam usahatani tersebut. Wawancara yaitu mengadakan tanya jawab secara langsung dengan responden, menggunakan kuisioner untuk mengetahui tentang objek yang sedang diteliti.

Data sekunder dikumpulkan berdasarkan laporan-laporan tertulis yang dilakukan pada usahatani bayam dan juga dilakukan dengan membaca atau mempelajari buku-buku teks, laporan-laporan penelitian terdahulu, internet dan lembaga pemeritah terkait.

\subsection{Metode Penelitian}

Penelitian ini dilaksanakan pada bulan Januari 2012, bertempat di Kelurahan Sasa Kecamatan Ternate Selatan yang merupakan salah satu sentra budidaya tanaman bayam. Penelitian ini menggunakan metode kuantitatif, yakni mendiskripsikan hasil dengan menggunakan analisis biaya dan analisis BEP.

\subsection{METODE ANALISIS DATA}

\subsubsection{Analisis Biaya}

Untuk mengetahui berapa besar biaya produksi yang dikeluarkan dalam usahatani tanaman bayam dengan melakukan perhitungan biaya yang dikeluarkan untuk masing-masing input. Untuk mengetahui total biaya yang dikeluarkan tersebut secara matematis dapat dihitung dengan memakai rumus sebagai berikut (Firdaus Muhammad, 2007) :

$$
\mathrm{TC}=\mathrm{FC}+\mathrm{VC}
$$

Dimana :

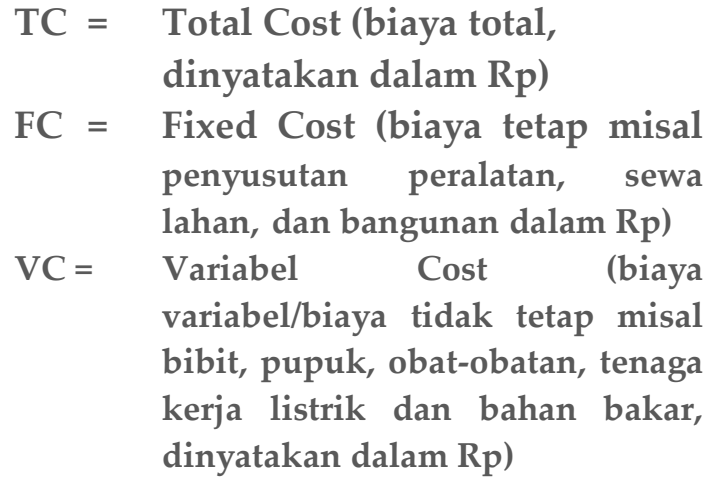

\subsubsection{Analisis Penerimaan}

Analisis penerimaan digunakan untuk mengetahui besarnya penerimaan yang diterima oleh produsen usahatani tanaman bayam di Kelurahan Sasa Kecamatan Kota Ternate Selatan. Untuk mengetahui total penerimaan tersebut, secara matematik dapat dihitung dengan memakai rumus :

$$
\mathrm{TR}=\mathbf{P} \times \mathbf{Q}
$$




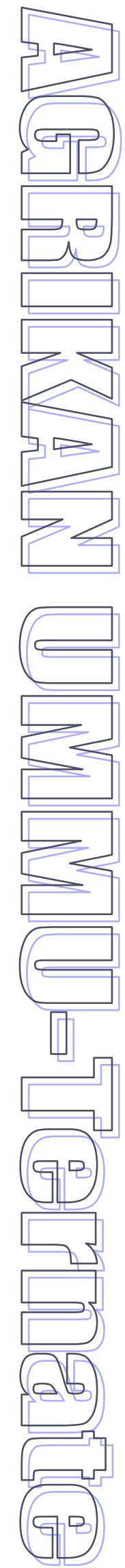

Dimana :

$$
\begin{aligned}
\mathrm{TR}= & \text { Total Revenue (penerimaan } \\
& \text { total, dinyatakan dalam Rp) } \\
\mathbf{P}= & \text { Price (harga, dinyatakan dalam } \\
& \text { Rp) } \\
\mathbf{Q}= & \text { Quantity (jumlah produksi) }
\end{aligned}
$$

\subsubsection{Analisis Pendapatan}

Untuk menganalisis pendapatan yang diperoleh pengusaha alam memproduksi bayam, maka dapat digunakan analisis yang dikemukakan oleh Mosher (1998) sebagai berikut :

$$
\pi=\mathrm{TR}-\mathrm{TC}
$$

Dimana :

$$
\begin{aligned}
\pi= & \text { keuntungan/pendapatan } \\
\mathrm{TR}= & \text { Total Revenue (penerimaan total, } \\
& \text { dinyatakan dalam } \mathrm{Rp}) \\
\mathrm{TC}= & \text { Total Cost (biaya total, dinyatakan } \\
& \text { dalam } \mathrm{Rp})
\end{aligned}
$$

\subsubsection{Analisis Efisiensi Usaha}

Untuk mengukur tingkat efisiensi usaha dalam proses produksi usahatani tanaman bayam digunakan analisis $\mathrm{R} / \mathrm{C}$ ratio dengan rumus :

$\mathrm{RC}$ ratio $=\mathrm{TR} / \mathrm{TC}$

$$
\begin{aligned}
\text { Dimana } \quad: \\
\text { TR }=\text { Total Revenue (penerimaan total) } \\
\text { TC }=\text { Total Cost (biaya total) }
\end{aligned}
$$

Apabila hasil analisis :

$\mathrm{R} / \mathrm{C}$ ratio $>1$, maka usaha tersebut efisiensi dan menguntungkan untuk diusahakan

$\mathrm{R} / \mathrm{C}$ ratio $=1$, maka usaha tersebut tidak rugi dan tidak untung (impas)

$\mathrm{R} / \mathrm{C}$ ratio $<1$, maka usaha tersebut tidak efisiensi atau tidak menguntungkan untuk diusahakan.

\subsubsection{Analisis Break Even Point (BEP)}

Untuk mengetahui kondisi Break Even Point (BEP) pada usaha tani tanaman bayam dikenal beberapa konsep BEP, diantaranya BEP Penerimaan, BEP Produksi, dan BEP Harga.
Menurut Suratiyah (2006), bahwa formula atau rumus untuk menghitung nilai dari beberapa BEP adalah sebagai berikut :

\subsubsection{BEP Penerimaan}

BEP Penerimaan $(R p)=\frac{F C}{1-\frac{\mathrm{VC}}{\mathrm{S}}}$

\subsubsection{BEP Produksi}

$$
\text { BEP Produksi (Ikat) }=\frac{\text { FC }}{\mathrm{P}-\mathrm{AVC}}
$$

\subsubsection{BEP Harga}

$$
\text { BEP Harga }(\text { Rp/Ikat })=\mathrm{TC} / \mathrm{Y}
$$

Dimana :

$$
\begin{array}{ll}
\mathrm{FC} & =\text { Biaya Tetap } \\
\mathrm{VC} & =\text { Biaya Variabel } \\
\mathrm{S} & =\text { Penerimaan } \\
\mathrm{FC} & =\text { Biaya Tetap } \\
\mathrm{P} & =\text { Harga Produk } \\
\mathrm{AVC} & =\text { Nilai Rata-rata Biaya Variabel } \\
\mathrm{TC} & =\text { Total Cost atau Biaya Total }(\mathrm{Rp}) \\
\mathrm{R} & =\text { Total Produksi }(\mathrm{Rp})
\end{array}
$$

Kriteria yang akan dicapai :

BEP < produksi ditingkat produsen, maka usaha tersebut menguntungkan atau efisien untuk diusahakan

BEP = produksi ditingkat produsen, maka usaha tersebut dikatakan impas

BEP > produksi ditingkat produsen, maka usaha tersebut dikatakan rugi atau tidak efisien untuk diusahakan.

\section{HASIL DAN PEMBAHASAN}

\subsection{Analisis Biaya}

Analisis biaya merupakan pengukuran semua nilai yang dikorbankan dari berbagai input selama berlangsungnya proses produksi untuk menghasilkan output.

Biaya variabel yang digunakan dalam produksi bayam terdiri dari bibit, pupuk, pestisida, dan biaya tenaga kerja.Besarnya total biaya variabel yang dikeluarkan rata-rata Rp. 151.333,33.Total biaya penyusutan alat adalah sebesar Rp. 280.500 . Total biaya tetap iuran anggota dan listrik yang dikeluarkan oleh setiap petani responden per bulan (per musim tanam) rata-rata sebesar Rp. 65.000. Jenis biaya terbesar adalah iuran anggota yaitu 


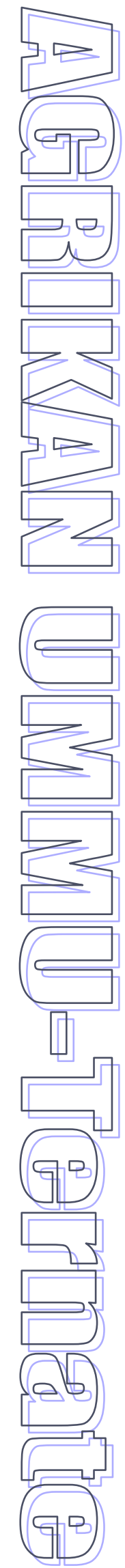

rata-rata $\mathrm{Rp} .40 .000$ dan terkecil adalah rata-rata Rp. 25.000. Biaya total yang dikeluarkan oleh petani responden dalam sekali proses produksi usahatani tanaman bayam adalah sebesar $\mathrm{Rp}$. 16.405.000, dengan rata-rata biaya total $R p$. $546.833,33$.

\subsection{Penerimaan}

Penerimaan merupakan jumlah produk yang dihasilkan dalam produksi dikalikan dengan harga jual produk. Tiap-tiap produsen usahatani bayam di Kelurahan

Total penerimaan sebesar Rp. 40.500.000, yaitu sebagai berikut ; bayam merah sebanyak 60 petak dan menghasilkan 3000 ikat dengan nilai jual per ikat sebesar Rp. 6000, sehingga bayam merah mendapatkan penerimaan sebesar Rp. 18.000.000. Sedangkan bayam hijau sebanyak 90 petak dan menghasilkan 4500 ikat dengan nilai jual per ikat sebesar Rp. 5000, sehingga bayam hijau mendapatkan penerimaan sebesar Rp. 22.500.000.

\subsection{Pendapatan/Keuntungan}

Pendapatan atau keuntungan akan didapat setelah mengetahui nilai biaya dan nilai penerimaan. Besarnya pendapatan atau keuntungan dapat dilihat pada Tabel 2 .

\subsection{R/C Ratio}

Analisis RC ratio digunakan untuk mengetahui tingkat efisiensi usahatani tanaman bayam secara finansial. Efisiensi usahatani tanaman bayam bisa ditentukan dengan menghitung per cost ratio yaitu pembagian antara penerimaan suatu usaha dengan total biaya produksi.

Setelah mengetahui niai penerimaan dan nilai biaya, maka dapat dihitung nilai $\mathrm{R} / \mathrm{C}$ ratio. R/C Ratio pada usahatani bayam di Kelurahan Sasa Kecamatan TernateS\&selatan sebeKacakpatan Ternate Sela 2,4687 , yang artinya $R / C$ ratio $>1$. Maka usaha tersebut efisien dan menguntungkan. Nilai R/C ratio 2,4687 berarti dengan mengeluarkan biaya sebesar 1 satuan maka akan menghasilkan penerimaan sebesar 2,4687 satuan. Contoh jika mengeluarkan biaya sebesar Rp.100.000, maka akan menghasilkan penerimaan sebesar Rp. 246.870.

\subsection{Analisis Break Even Point (BEP)}

Analisis BEP digunakan untuk menghitung besarnya penerimaan dan produksi yang harus dicapai agar petani memperoleh keuntungan, serta harga jual yang menentukan apakah petani mendapat keuntungan dari total biaya produksi yang telah dikeluarkan.

Tabel 1. Penerimaan produksi usahatani tanaman bayam di Kelurahan Sasa Kecamatan Ternate Selatan

\begin{tabular}{ccccc}
\hline No. & Jenis Bayam & $\begin{array}{c}\text { Produksi } \\
\text { (ikat) }\end{array}$ & $\begin{array}{c}\text { Harga Jual } \\
\text { (Rp/ikat) }\end{array}$ & $\begin{array}{c}\text { Penerimaan } \\
\text { (Rp) }\end{array}$ \\
\hline 1 & Merah & 3000 & 6.000 & 18.000 .000 \\
2 & Hijau & 4500 & 5.000 & 22.500 .000 \\
\hline & Jumlah & 7500 & 11.000 & 40.500 .000 \\
\hline & Rata-rata & 250 & 366,67 & 1.350 .000 \\
\hline
\end{tabular}

Sumber data : Data primer yang diolah, 2012

Tabel 2. Pendapatan produksi usahatani tanaman bayam di Kelurahan Sasa Kecamatan Ternate Selatan

\begin{tabular}{cccc}
\hline No. & Penerimaan $(\mathrm{Rp})$ & Total Biaya $(\mathrm{Rp})$ & Pendapatan $(\mathrm{Rp})$ \\
\hline 1 & 40.500 .000 & 16.405 .000 & 24.095 .000 \\
\hline \multicolumn{3}{r}{ Jumlah } & 24.095 .000 \\
\hline \multicolumn{3}{r}{ Rata-rata } & $803.166,67$ \\
\hline
\end{tabular}

Sumber : Data primer yang diolah, 2012 
Tabel 3. Total penerimaan dan total biaya usahatani bayam dalam sekali produksi

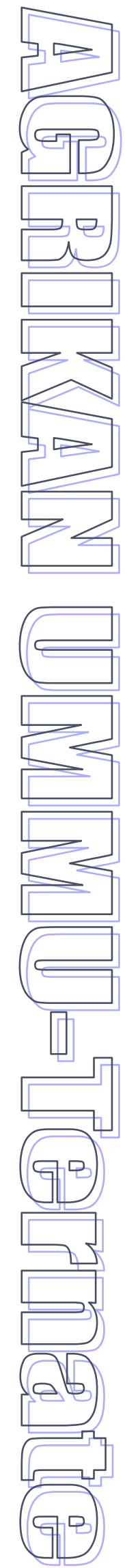

\begin{tabular}{|c|c|c|}
\hline No. & Uraian & Nilai (Rp) \\
\hline 1 & Total Penerimaan & 40.500 .000 \\
\hline 2 & Total Biaya & 16.405 .000 \\
\hline
\end{tabular}

Sumber data : Data primer diolah tahun 2011

Tabel 4. Break Even Point (BEP) Penerimaan Usahatani Tanaman Bayam

\begin{tabular}{ccccc}
\hline No. & Jenis Bayam & $\begin{array}{c}\text { FC = Biaya } \\
\text { Tetap (Rp) }\end{array}$ & $\begin{array}{c}\text { VC = Biaya } \\
\text { Variabel (Rp) }\end{array}$ & $\begin{array}{c}\mathrm{S}=\text { Penerimaan } \\
(\mathrm{Rp})\end{array}$ \\
\hline 1 & Merah & \multirow{2}{*}{10.365 .000} & 6.040 .000 & 18.000 .000 \\
2 & Hijau & & 22.500 .000 \\
\hline & Jumlah & 40.500 .000 \\
\hline
\end{tabular}

Sumber : Data primer yang diolah, 2012

Tabel 5. Break Even Point (BEP) Produksi Tanaman Bayam

\begin{tabular}{ccccc}
\hline No. & $\begin{array}{c}\text { Jenis } \\
\text { Bayam }\end{array}$ & $\begin{array}{c}\text { FC = Biaya } \\
\text { Tetap (Rp) }\end{array}$ & $\begin{array}{c}\mathrm{P}=\text { Harga Produk } \\
\text { (Rp/lkat) }\end{array}$ & $\begin{array}{c}\text { AVC= Rat-rata Biaya } \\
\text { Variabel/Produksi (Rp/lkat) }\end{array}$ \\
\hline 1 & Merah & 10.365 .000 & 6000 & 2013 \\
2 & Hijau & 10.365 .000 & 5000 & 1342 \\
\hline
\end{tabular}

Sumber : Data primer yang diolah, 2012

Hasil analisis tiga BEP tampak bahwa usahatani tanaman bayam mengalami keuntungan dan layak untuk dikembangkan, jika penerimaan (Rp. 40.500.000) > dari BEP penerimaan yang diperoleh petani sebesar Rp. 12.181.219 per musim tanam, produksi total tanaman bayam (7500 ikat) > BEP produksi 5432 ikat, dan begitu juga dengan harga jual (bayam merah Rp. 6000/ikat, bayam hijau Rp. 5000/ikat ) > BEP harga Rp. 5468/ikat (bayam merah), Rp. $3645 /$ ikat bayam hijau.

\section{PENUTUP}

Berdasarkan hasil penelitian yang dilakukan, analisis usahatani tanaman bayam di Kelurahan Sasa Kecamatan Ternate Selatan Kota Ternate dapat disimpulkan bahwa :

1. Besaran total biaya dari masing-masing biaya variabel dan biaya tetap dalam sekali produksi usahatani tanaman bayam sebagai berikut : Biaya variabel Rp. $\quad 6.040 .000$ (benih bayam, pupuk, pestisida, dan biaya tenaga kerja). Sedangkan biaya tetap sebesar
Rp. 10.365.000 (penyusutan alat, iuran anggota, dan biaya listrik). Jadi biaya total sekali produksi usahatani tanaman bayam yaitu sebesar Rp. 16.405.000,--

2. Penerimaan dari masing-masing jenis bayam dalam sekali produksi, antara lain : Bayam merah sebesar Rp. 18.000.000 dan bayam hijau sebesar Rp. 22.500.000. Jadi penerimaan total dari produksi bayam secara keseluruhan adalah sebesar $\mathrm{Rp}$. 40.500.000,--

3. Pendapatan total dari usahatani tanaman bayam dalam sekali produksi yaitu sebesar Rp. 24.095.000,--

4. Nilai R/C rasio usahatani tanaman bayam sebesar 2,4687. Ini menandakan usahatani tersebut efisien dan menguntungkan sehingga layak dikembangkan.

5. Nilai Break Even Poin (BEP) penerimaan, produksi, dan harga lebih kecil dari total penerimaan, produksi, dan harga. Dengan demikian usahatani tanaman bayam dapat menguntungkan dan layak dikembangkan. 
